\title{
First Record of the Field-Cricket Turanogryllus eous (Orthoptera: Gryllidae: Gryllinae) from Korea
}

\author{
Tae-Woo Kim* \\ National Institute of Biological Resources, Incheon 404-170, Korea
}

\begin{abstract}
The field-cricket Turanogryllus eous Bey-Bienko, 1956 and its genus Turanogryllus Tarbinsky, 1940 were recorded for the first time from Chungcheongbuk-do province in Korea to carry out the project 'The sound guides to Korean animals.' Depending on the discovery of the cricket, its distributional ranges are more widened towards East Asia to the Korean peninsula from China mainland, the Turanogryllus was 10th to known Gryllinae genera in Korea. Description, photos of habitus, figure of male genitalia, oscillogram and spectrogram for the calling sound are provided for aid identification. Voucher specimens are deposited in the collection of National Institute of Biological Resources, Incheon, Korea.
\end{abstract}

Keywords: Orthoptera, Gryllidae, Gryllinae, Turanogryllus eous, new record, Korea

\section{INTRODUCTION}

One of the field-cricket genus Turanogryllus was established by Tarbinsky (1940). Until now, 32 species have been described throughout the world from Eurasia (Afghanistan, Arabia, China, Iran, Israel, and Russia), Indo-Malaysia (India, Laos, Nepal, and Pakistan), and Africa (Angola, Egypt, Guinea, Kenya, Sierra Leon, Zaire, and Zambia) (Otte, 1994).

Diagnostic characters of the genus Turanogryllus are as follows, they are beings with distinct sexual differences between male and female on their tegmina. The most striking feature is the presence of styli on the external apical corners of the epiphallus in male genitalia (Randell, 1964). Until now, the genus was not recognized from Korea. The only known nine genera in the Gryllinae are Comidoblemmus, Gryllodes, Gryllus, Loxoblemmus, Mitius, Modicogryllus, Phonarellus, Teleogryllus and Velarifictorus (Paek et al., 2010).

To carry out the project 'The sound guides to Korean animals' that was designed in 2010, I have been focusing on listening to cricket sounds in field survey. In the year 2010, during the course of the project, although unfamiliar yet very distinctive cricket's calling sound was heard from Chungju City province. By tracing the sound only one male living specimen was captured, by short period rearing in the acoustic laboratory and the sound was recorded in good quality (hear Kim, 2011). Second year in 2011, my colleague Mr. Sung Ki-Soo informed me that he had found a habitat of the field-cricket from the Jecheon City province near Chungju City. The collecting was successful for more confirmation.

Based on the microscopic observation of the specimens and morphological comparison from the earlier literatures, the field-cricket was identified to be 'Turanogryllus eous Bey-Bienko, 1956' which was described originally in Tsingtau, China. The cricket is well introduced as one of the Chinese singing crickets (Wu, 2001). Only known from China's mainland, its distribution ranges are across Beijing, Shandong, Jiangsu, Zhejiang, Guangxi, and Hunan (Hua, 2000). A taxonomic key is presented for the three Chinese species of Turanogryllus in Yin and Liu (1995) and recently, the fourth species was described from Shaanxi province in $\mathrm{Li}$ and Zheng (1998).

Depending on the discovery of the field-cricket, its distributional ranges are now more widened towards East Asia to the Korean peninsula. The species and the genus are both newly recognized in Korean fauna. All voucher specimens are deposited in the dry collections of the National Institute of Biological Resources. Sound recording was accomplished by using the digital recorder (PCM D-50; SONY, Tokyo, Japan), the oscillogram and spectrogram are drawn by Raven Pro 1.3 (Cornell Lab of Ornithology). Terminology for description refers to Randell (1964), Otte and Alexander (1983). (c) This is an Open Access article distributed under the terms of the Creative Commons Attribution Non-Commercial License (http://creativecommons.org/ licenses/by-nc/3.0/) which permits unrestricted non-commercial use, distribution, and reproduction in any medium, provided the original work is properly cited.

pISSN 2234-6953 eISSN 2234-8190
*To whom correspondence should be addressed

Tel: 82-32-590-7245, Fax: 82-32-590-7069

E-mail: pulmuchi@korea.kr 


\section{SYSTEMATIC ACCOUNTS}

Order Orthoptera Olivier, 1789

Family Gryllidae Laicharting, 1781

Subfamily Gryllinae Laicharting, 1781

Genus Turanogryllus Tarbinsky, 1940

Type species: Gryllus lateralis Fieber, 1853

Diagnosis. Head globose, body cylindrical. Male tegmina well developed, but those of the female are generally reduced to small pads, thus they look like immature nymph. Male subgenital plate concave or deeply notched; dorsal lobes of ectoparameres externally visible; styli presence on the posterolateral corners of epiphallus. Ovipositor straight, slender needle-shaped.

1*Turanogryllus eous Bey-Bienko, 1956 (Figs. 1-4)

Turanogryllus eous Bey-Bienko, 1956: 221, figs. 1, 2. "China:

Tsingtau". Syntype is deposited in the Zoological Institute of the Russian Academy of Sciences, St. Petersburg, Russia.

Material examined (12 specimens). Korea: Chungcheongbuk-do: $1 \sigma^{7}$, Chungju City, Gageum-myeon, Chungju Expressway Resting Place (a down line), 25 Aug 2010, Kim TW; 6 구우, Jecheon City, Cheongpung-myeon, Dan-ri, 4 Sep 2011, Sung KS.

Description. General: Body coloration brownish dark black, ventral parts and appendages more bright creamy yellow. Male body fusiform, with well developed wide tegmina that cover the whole abdomen; female body cylindrical, with short small tegmina that just cover to only the basal second abdominal tergites.

Male (Fig. 1A). Head (Fig. 2A): Roundly globular, weakly wider than the anterior margin of pronotum and the occiput with six bright longitudinal strips posteriorly. Vertex dark black colored with fine ecdysis ' $\mathrm{Y}$ ' line; distance between the antennal sockets as wide as the greatest horizontal diameter of an eye. Lower margin of the antennal socket slightly
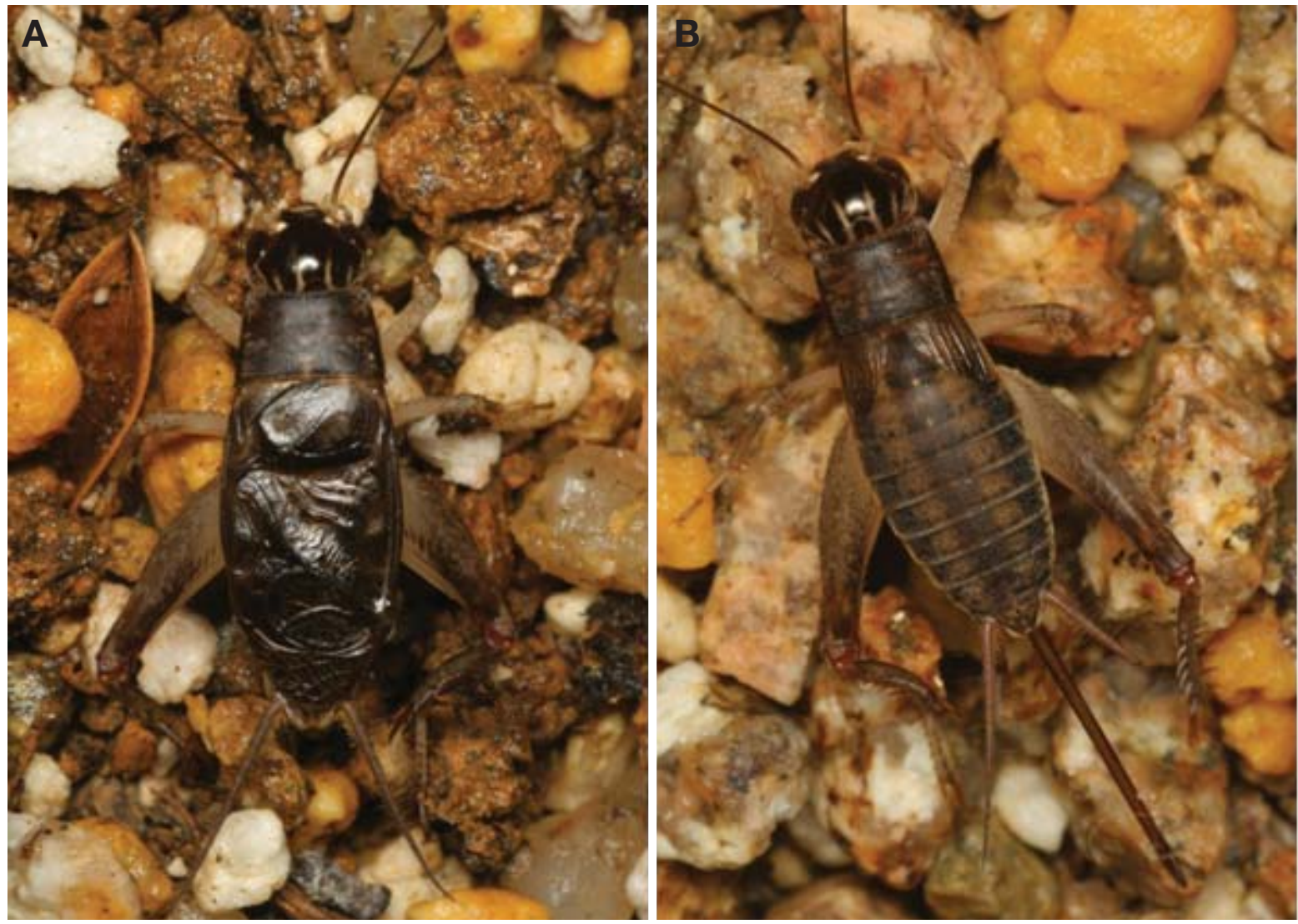

Fig. 1. Habitus of Turanogryllus eous Bey-Bienko, 1956 from Korea. A, Male; B, Female.

Korean name: ${ }^{1 *}$ 각시귀뚜라미 (신칭) 

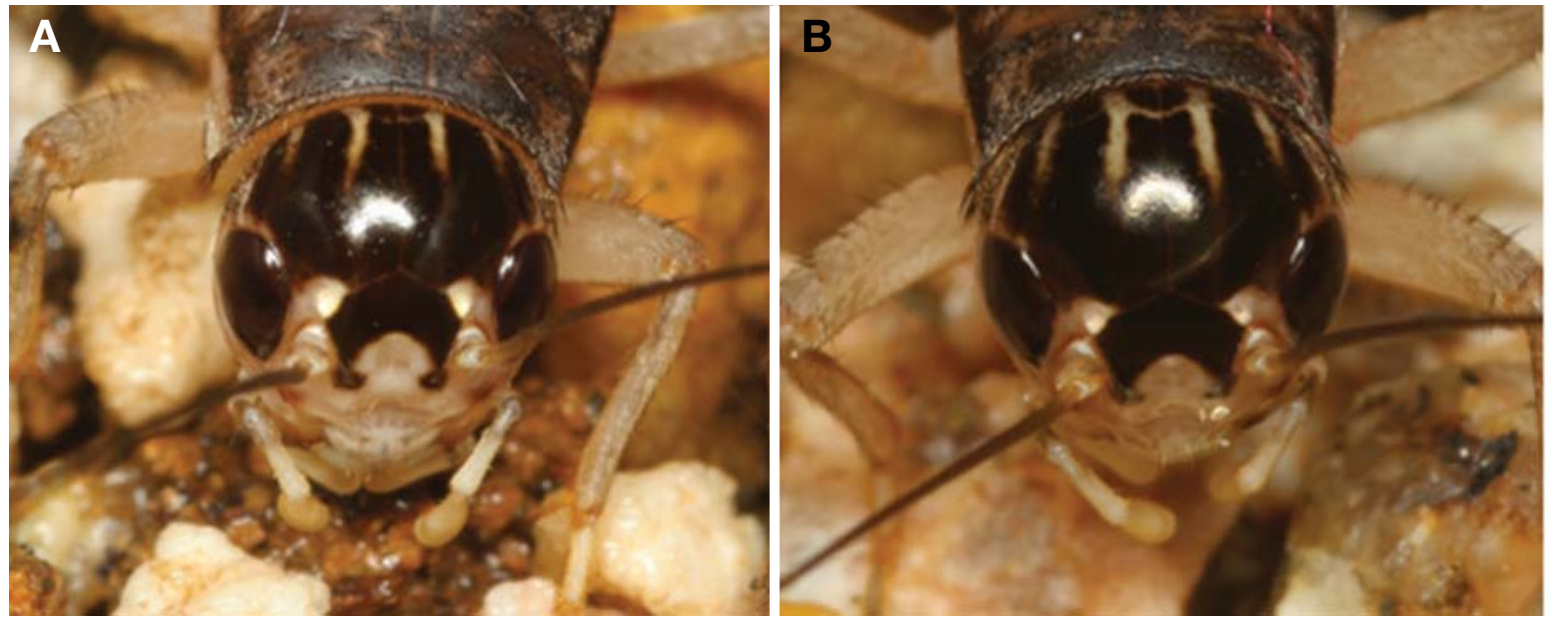

Fig. 2. Head shape of Turanogryllus eous Bey-Bienko, 1956 from Korea. A, Male; B, Female.

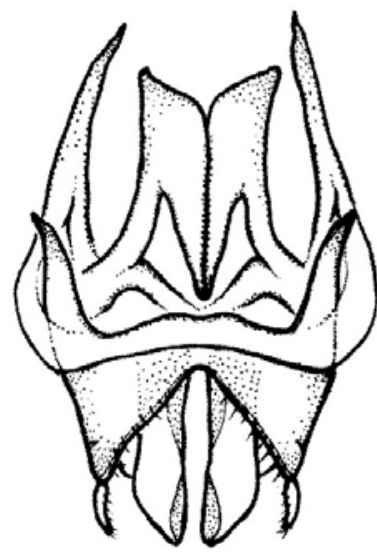

A

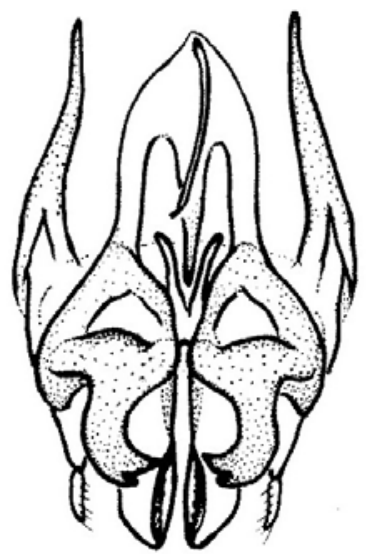

B

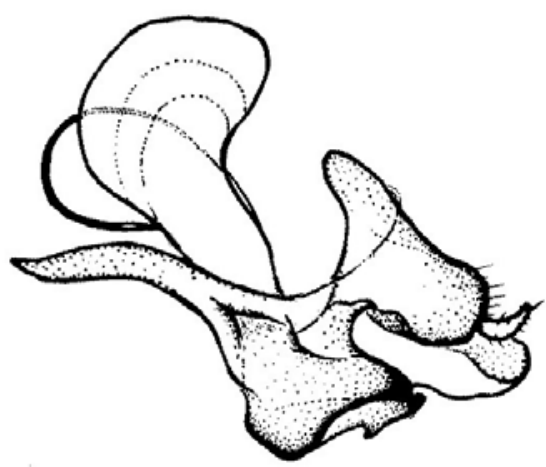

C

Fig. 3. Male genitalia of Turanogryllus eous Bey-Bienko, 1956 from Korea. A, Dorsal view; B, Ventral view; C, Lateral view. Scale bar $=1.5 \mathrm{~mm}$.

located higher than the lower margin of an eye. Median ocellus surrounded by the bright color region. Lateral ocelli also brightly encircled. Clypeal suture sinuately transverse in the mid toward above. Mouth parts and palpi clearly bright cream in color. Antennal scape as long as the width, without projection.

Thorax: Pronotum 1.8 times wider than the length in dorsal view, its longitudinal length shorter than the fore femur; anterior margin smoothly concave; posterior margin truncated and wider than the anterior margin. Along both the margins with dense bristles, setose. Dorsal surface with a pair of black crescent-shaped markings. Lateral lobe of pronotum as deep as the width and its lower half area clearly bright; lower anterior margin rather angularly round; lower hind margin widely round, shorter than the lower anterior margin. Mesosternum forms a pair of lobes posteriorly; metasternum not divided.

Wings: Tegmina macropterous, covers the abdominal end and wider than the posterior margin of pronotum; harp veins three or four, sinuated; chordal veins three; mirror area divided, 1.5 times wider than the length; apical area well netted, 0.8 times shorter than the mirror area; lateral field deeper than the lateral lobe of pronotum, with seven or eight longitudinal veins; upper half area is darkish in color, lower one is bright creamy yellow in color. Hind wings degenerated to small plume-shaped.

Legs: Fore tibia with oval-shaped outer tympanum, 2.5 times longer than the width; inner tympanum hardly discernable, not distinguished; ventral apical spurs three. Middle tibia with two pairs of apical spurs, among them the outer posterior 
one shortest. Hind femur 2.5 times longer than the middle femur. Hind tibia with seven pairs of dorsal spines on both the sides, except for the two pairs of apical spurs; largest inner apical spur 0.4 times shorter than the basitarsus. Hind basitarsus two times longer than the combining length of the remaining two apical tarsomeres; dorsal spinules inner one five, outer one seven; inner apical spur 0.7 times shorter than the length of last tarsomere. All tarsomeres with numerous ventral bristles.

Abdomen: Cercus 0.8 times shorter than the hind femur. Subgenital plate widely rounded and upwardly recurved; hind margin with a V-shaped notch in mid, it forms a pair of lobes. Epiproct triangular, with a median longitudinal furrow; lateral margins sinuated near the base of both the sides; apex narrowly truncated, beak-shaped. Dorsal lobes of ectoparameres slightly visible, main genitalia hidden upon subgenital plate.

Genitalia (Fig. 3): Epiphallus with a deeply emarginated posterior margin, which penetrated into two thirds of the entire length of the epiphallus; lateral lobes with short styli at their posterior apices. Ectoparameres divided apically into dorsal and ventral lobes; dorsal lobe lamelliform, weakly recurved in its posterior half, inner ventral margin serrulated; ventral lobe digitiform, sigmoidally curved, its apex divided into three tooth-like small lobes; basal median corners of the dorsal lobe, connects with the semicircular sclerotic arch.
Endoparameres with an expanded parameral muscle insertion at its base. Virga simply broad in its lateral view, apically short and unmodified. Rami divided at their dorsal ends, into a long dorsal process and a short ventral process. Ventral process associated with the base of the ectoparamere.

Female (Figs. 1B, 2B): Size and general appearance similar to the male, but tegmina remarkably shorter, thus the abdominal dorsal parts almost visible. Tegmina as long as, or slightly shorter than the longitudinal length of the pronotum, which not overlapped on the dorsum of the abdomen; inner margin oblique outwards and the tegminal apex angularly rounded; lateral field as deep as lateral lobe of pronotum, with five longitudinal veins. Subgenital plate trapezoidal, simply smaller than in the male, 1.8 times wider than the length; posterior margin narrower, U-shaped. Ovipositor straight needle-shaped, subapically swollen and slightly longer than the hind femur; apex sharply pointed, without serration.

Measurements (dry specimens in $\mathbf{m m}$ ). Lengths of body 구 12.9-14.2, 우 12.5-15.8; pronotum o 2.9-3.1, 우 2.93.3; tegmen $\sigma^{7}$ 9.1-10.2, 우 2.0-3.0; hind femur o $\sigma^{7}$ 8.89.7, 우 9.6-10.9, ovipositor 우 11.0-12.8.

Calling sound (Fig. 4). Males are acoustically active both day and night. They stay in the cavity under rocks, or hide within the grass vegetation. Calling sound consists of a series of song phrases with an undulating 1-9 pitches that are based
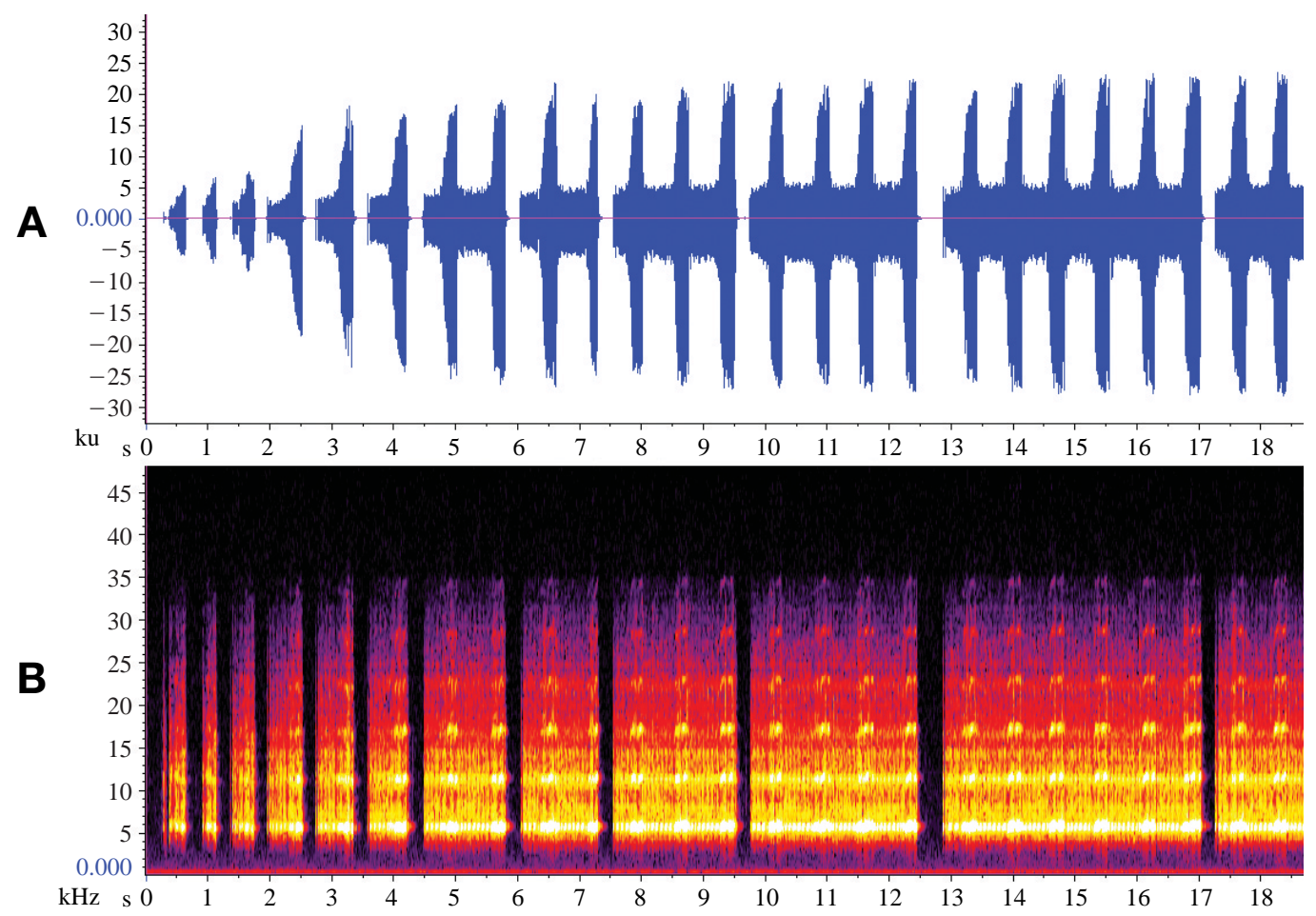

Fig. 4. Calling sound of a male of Turanogryllus eous Bey-Bienko, 1956 from Korea (day, $28^{\circ} \mathrm{C}$ ). A, Oscillogram; $B$, Spectrogram. 
on each time of interlude for 0.6-0.8 $\mathrm{s}$ and their interval time was $0.2-0.35 \mathrm{~s}$ at $28^{\circ} \mathrm{C}$ condition. Each syllable lasted to about 0.01 seconds during the interludes and 0.02-0.025 s during the each pitch. The dominant frequency spectrum was 5-16 $\mathrm{KHz}$.

Distribution. Korea (new record) and China.

Remarks. Genitalic description of the type species Turanogryllus lateralis in Randell (1964) was actually based on the misidentification of Turanogryllus eous, as already mentioned as in Bey-Bienko (1971) and Gorochov (1985). The figures of the genitalia are also well agreed with the Korean specimens used in this study. Bey-Bienko (1956) described Turanogryllus eous as a new species compared with the earlier records of Gryllodes koshunensis Shiraki, 1911 from mainland China (Hsu, 1931; Wu, 1935). Even the type locality of Gryllodes koshunensis is Taiwan (=Formosa), both superficially resembled to each other, but they have differences in the color patterns of strips on occiput, tegminal venation of male, and a few female's characters (Bey-Bienko, 1956), not in synonymic relationship (Otte, 1994). Generic position of Gryllodes koshunensis was already suspected by its author (Shiraki, 1930), later transferred to Gryllopsis koshunensis since Chopard (1967). But its combination must be now reconsidered as Velarifictorus koshunensis (personal communication with Dr. Yang Jeng-Tze, National Chung Hsing University, Taiwan).

\section{ACKNOWLEDGMENTS}

The author heartily thank to Mr. Sung Ki-Soo, the free-lance entomologist provided valuable specimens of the field-crickets; Ms. Lee Jung-Sook (National Institute of Biological Resources), the librarian give me great helps for asking literatures and the translation of Russian; Dr. Kim Hwa-Jung (National Institute of Biological Resources), the ornithologist guided me using the sound analysis program, Raven Pro; Dr. Jin Xingbao (Shanghai Science \& Technology Museum), the colleague entomologist provided valuable literature on Chinese cricket. This study was supported by the project 'The sound guides to Korean animals' of the National Institute of Biological Resources (NIBR) under the Ministry of Environment, Korea.

\section{REFERENCES}

Bey-Bienko G, 1956. Investigations on the fauna and taxonomy of the Gryllidae (Orthoptera) of China. Zoologicheskii Zhurnal, 35:219-237.
Bey-Bienko G, 1971. Ergebnisse des Forschungsunternehmens Nepal Himalaya [On the Orthopteroid insects from Eastern Nepal]. Khumbu Himal, 4:55-57.

Chopard L, 1967. Pars 10. Gryllides. In: Orthopterum catalogus (Ed., Beier MW). Junk, Gravenhage, pp. 1-211.

Gorochov AV, 1985. On the fauna of Grylloidea (Orthoptera) of China. Entomologicheskoe Obozrenie, 64:89-109.

Hsu YC, 1931. A revised list of known species of crickets from the China coast. Bulletin of the Peking Society of Natural History, 5:17-25.

Hua LZ, 2000. List of Chinese insect. Zhongshan University Press, Guangzhou, pp. 32-57.

Kim TW, 2011. A sound guide to Korean crickets (Orthoptera: Ensifera: Grylloidea). National Institute of Biological Resources, Incheon, pp. 1-164.

Li K, Zheng Z, 1998. A new species of genus Turanogryllus from Shaanxi province, China (Orthoptera: Gryllidae). Journal of Shaanxi Normal University, Natural Science Edition, 26:119-120.

Otte D, 1994. Orthoptera species file 1: Crickets (Grylloidea). The Orthopterists' Society at the Academy of Natural Sciences of Philadelphia, Philadelphia, PA, pp. 1-120.

Otte D, Alexander RD, 1983. The Australian crickets (Orthoptera: Gryllidae). The Academy of Natural Sciences of Philadelphia, Monograph, 22:1-477.

Paek MK, Hwang JM, Jung KS, Kim TW, Kim MC, Lee YJ, Cho YB, Park SW, Lee HS, Ku DS, Jeong JC, Kim KG, Choi DS, Shin EH, Hwang JH, Lee JS, Kim SS, Bae YS, 2010. Checklist of Korean insects. Nature and Ecology, Academic Series 2, Seoul, pp. 1-598.

Randell RL, 1964. The male genitalia in Gryllinae (Orthoptera: Gryllidae) and a tribal revision. The Canadian Entomologist, 96:1565-1607.

Shiraki T, 1911. Monographie der Grylliden von Formosa, mit der uebersicht der Japanischen Arten. General Government von Formosa, Taihoku, pp. 1-129.

Shiraki T, 1930. Orthoptera of the Japanese Empire. Part I. (Gryllotalpidae and Gryllidae). Insecta Matsumurana, 4:181-252.

Tarbinsky SP, 1940. The saltatorian orthopterous insects of the Azerbaidzhan S. S. R. Academy of Sciences in the Azyerbaidjankoi S. S. R., Moscow, Leningrad, pp. 1-245.

$\mathrm{Wu} \mathrm{CF}, 1935$. Catalogus Insectorum Sinensium [Catalogue of Chinese insects]. Vol. 1. The Fan Memorial Institute of Biology, Peiping, pp. 15-214.

$\mathrm{Wu}$ J, 2001. Atlas of Chinese sound-producing insects. Beijing Press, Beijing, pp. 1-316.

Yin HS, Liu XW, 1995. Synopsis on the classification of Grylloidea and Gryllotalpoidea from China. Shanghai Scientific and Technological Literature Publishing House, Shanghai, pp. 1-237. 